\title{
Espejos hispanorromanos de plomo. Un nuevo tipo de producción plúmbea detectado en la Península Ibérica
}

\author{
Joaquín Aurrecoechea Fernandez *
}

\section{RESUMEN}

Existen pocos ejemplares de espejos fabricados en plomo durante el Imperio Romano, algunos de los cuales han sido encontrados en nuestro país. En el presente artículo se dan a conocer los hallazgos de este tipo procedentes de Hispania. La importancia del lote de piezas que estudiamos radica en el desconocimiento actual sobre estas producciones romanas, inéditas en nuestras publicaciones nacionales.

\section{SUMMARY}

There are few examples of lead mirrors in Roman Empire, and a number of this pieces have been found in our country. This work studies all the finding, of this pattern, from Hispania. The importance of this lot,

\footnotetext{
* Universidad Autónoma de Madrid.
} 
is indicated by the unthankfulness present in national publications over these roman crafts.

\section{INTRODUCCIÓN}

Los objetos de índole metálica están viéndose revitalizados por el creciente interés que los investigadores de nuestro país demuestran hacia ellos (VV.AA., 1990). La carencia de obras de conjunto que caracteriza la fase actual de la investigación en la que nos encontramos obliga a publicar el mayor número posible de materiales, con el fin de construir unas bases sólidas en las que apoyar nuestros conocimientos sobre el fenómeno de la producción de objetos metálicos en Hispania. Uniéndonos a esta corriente, queremos dar a conocer un lote de piezas inéditas y ausentes del panorama científico español, al menos que sepamos. Nos referimos a una serie de espejos romanos de plomo, cuyo interés primordial radica en la procedencia del material, vinculado con la comunidad autónoma de Castilla-La Mancha, para la que contamos con una buena documentación metalistera '. A este interés habria que añadir el derivado del conocimiento de un nuevo tipo de objetos ejecutados en una materia, el plomo, que todavía se encuentra bastante desatendida en las publicaciones, posiblemente por el carácter decorativo que suelen presentar sus hermanos, los objetos realizados en bronce.

\section{INVENTARIO}

Para evitar reiteraciones innecesarias indicamos que todas las piezas de este inventario están fabricadas en plomo, habiendo sido fundidas en un molde bivalvo.

1 Queremos agradecer a la Dra. Fernández Ochoa, de la UA de Madrid, las amables indicaciones que han hecho posible este estudio, así como al Dr. Caballero Zoreda las facilidades ofrecidas en el MAN de Madrid. Igualmente agradecer a los Sres. Fernández de la Cigoña y Montero el acceso a los materiales fruto de sus exploraciones. 


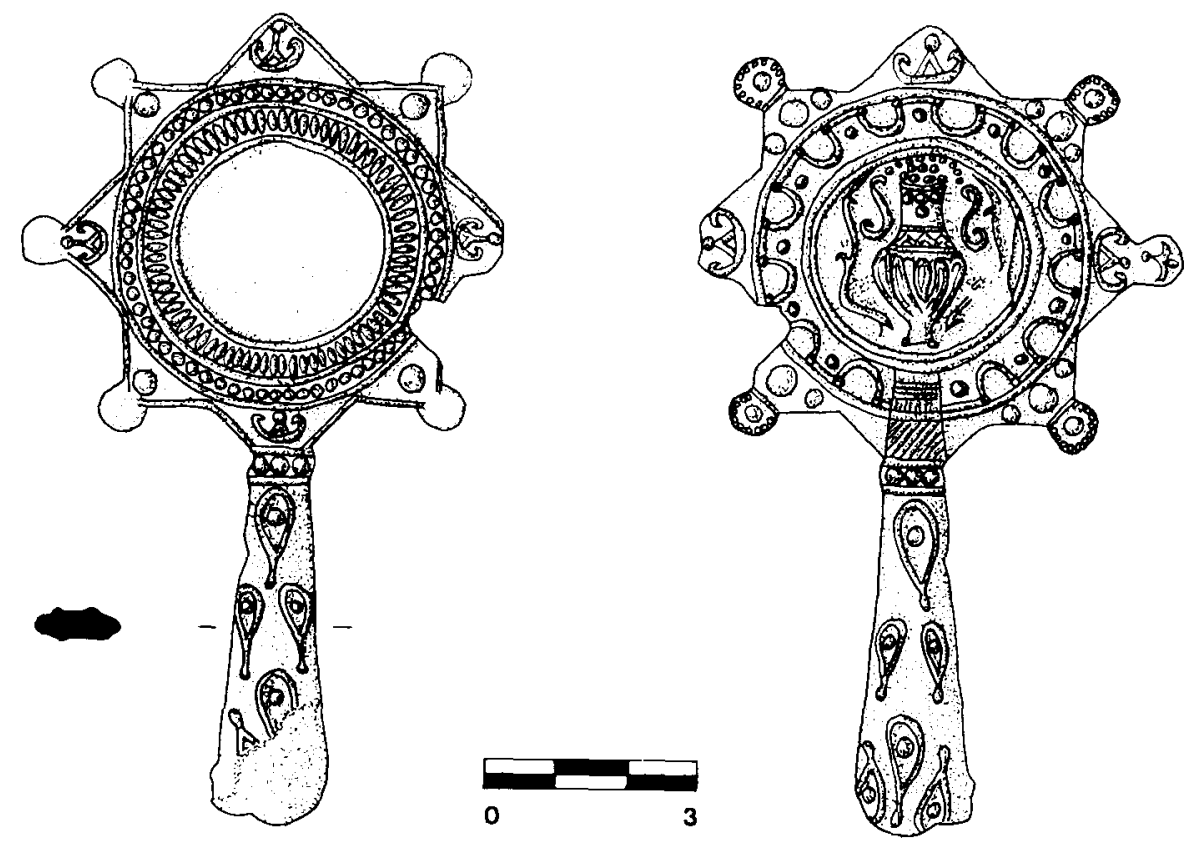

Fig. 1. Espejo de plomo de La Bienvenida (Almodóvar del Campo, Ciudad Real).

Núm. 1 (fig. 1)

Espejo completo, procedente de La Bienvenida (Núm. inv. BV/86/ 3341) y depositado en el Museo de Ciudad Real. La forma del mismo está constituida por dos cuadrados entrecruzados, que originan una estrella de ocho puntas. Seis de dichas puntas, aquellas que se disponen a uno y otro lado del eje, rematan en sendos casquetes de esfera. La decoración, muy elaborada, se dispone del siguiente modo: en el anverso, el contorno de la estrella está perfilado por una pequeña moldura cóncava, que limita ocho espacios triangulares en los que se alternan dos motivos: semiesferas y peltas. Dos coronas concéntricas, separadas por molduras, ocupan el espacio central de la pieza. La corona exterior se ornamenta con círculos y la interior por óvalos alargados. En el reverso, cuatro de las puntas terminadas en semiesferas, presentan un círculo central rodeado de otros menores, marcándose el tránsito con el espacio triangular mediante minúscula moldura. Este último espacio posee tres circulos en bateria, siendo el central de mayor tamaño. Intercaladas con 
las puntas anteriormente citadas, se encuentran otras tres, cuya decoración se asemeja a la descrita para el anverso del objeto, sólo que el motivo principal tiene una pequeña variante consistente en que la pelta ha perdido un travesaño, por lo que presenta un aspecto más triangular. El espacio central está ocupado por una crátera cargada de uvas, de asas en "S" y cuerpo agallonado, cuyo cuello se ornamenta con tres triángulos delimitados por molduras. Una corona radial, compuesta de arquillos de medio punto rematados en bolas y alternados con esferas, separan al cuerpo central del resto de la pieza.

El mango cuenta con una serie de decoraciones alargadas, con punto central, semejantes a gotas y tres esferas flanqueadas por molduras que unen este elemento al anteriormente descrito.

Las dimensiones del espejo son: $10,9 \mathrm{~cm}$ de longitud y $6,9 \mathrm{~cm}$ de ancho máximo.

Núm 2 (fig. 2)

Espejo completo depositado en el Museo Arqueológico Nacional (número 1970/59/2), sin procedencia conocida. La pieza es de forma discoidal, presentando el anverso una orla radial exterior con pequeñas esferas, que da paso a un espacio circular ornamentado con cabezas humanas, alternadas con figuras aladas, siendo las dos más cercanas al mango pájaros y las restantes pequeños cupidos en diversas actitudes. El reverso cuenta con una banda externa de roleos con pámpanos y hojas de hiedra, y un medallón central con jinete dispuesto a alanzear a un enemigo caido. Mango idéntico al precedente.

Las dimensiones de la pieza son: $11,2 \mathrm{~cm}$ de longitud y $6,4 \mathrm{~cm}$ de ancho máximo.

Núm. 3 (fig. 3, núm. 1)

Espejo incompleto procedente de El Quinto (Seseña, Toledo), depositado en la Colección Cigoña. La decoración consiste en una línea externa de esferas y motivo peltiforme, junto a la interna, formada por roleos con hojas de hiedra y pámpano. En el reverso observamos círcu- 
Espejos hispanorromanos de plomo. Un nuevo tipo de producción ...
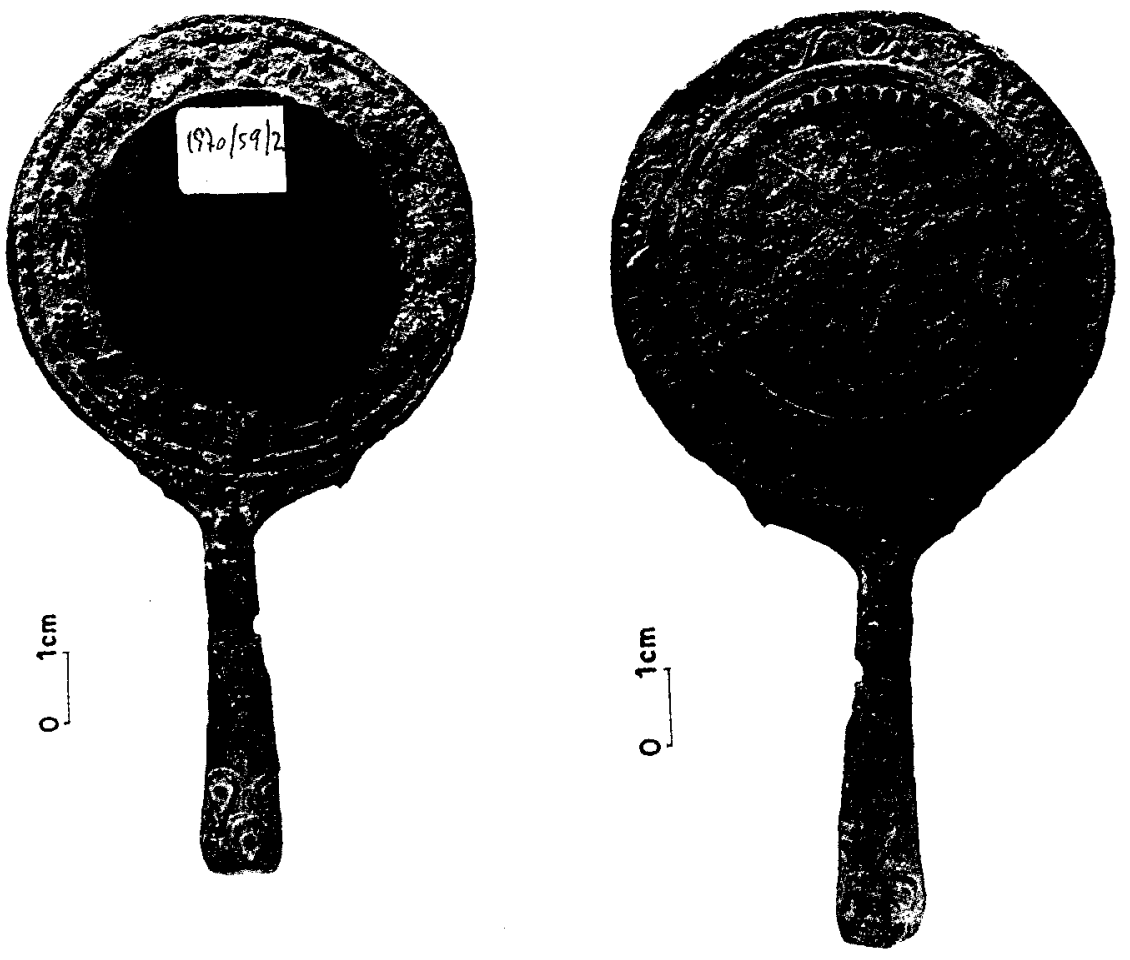

Fig. 2. Espejo de plomo del Museo Arqueológico Nacional de Madrid, sin procedencia. 

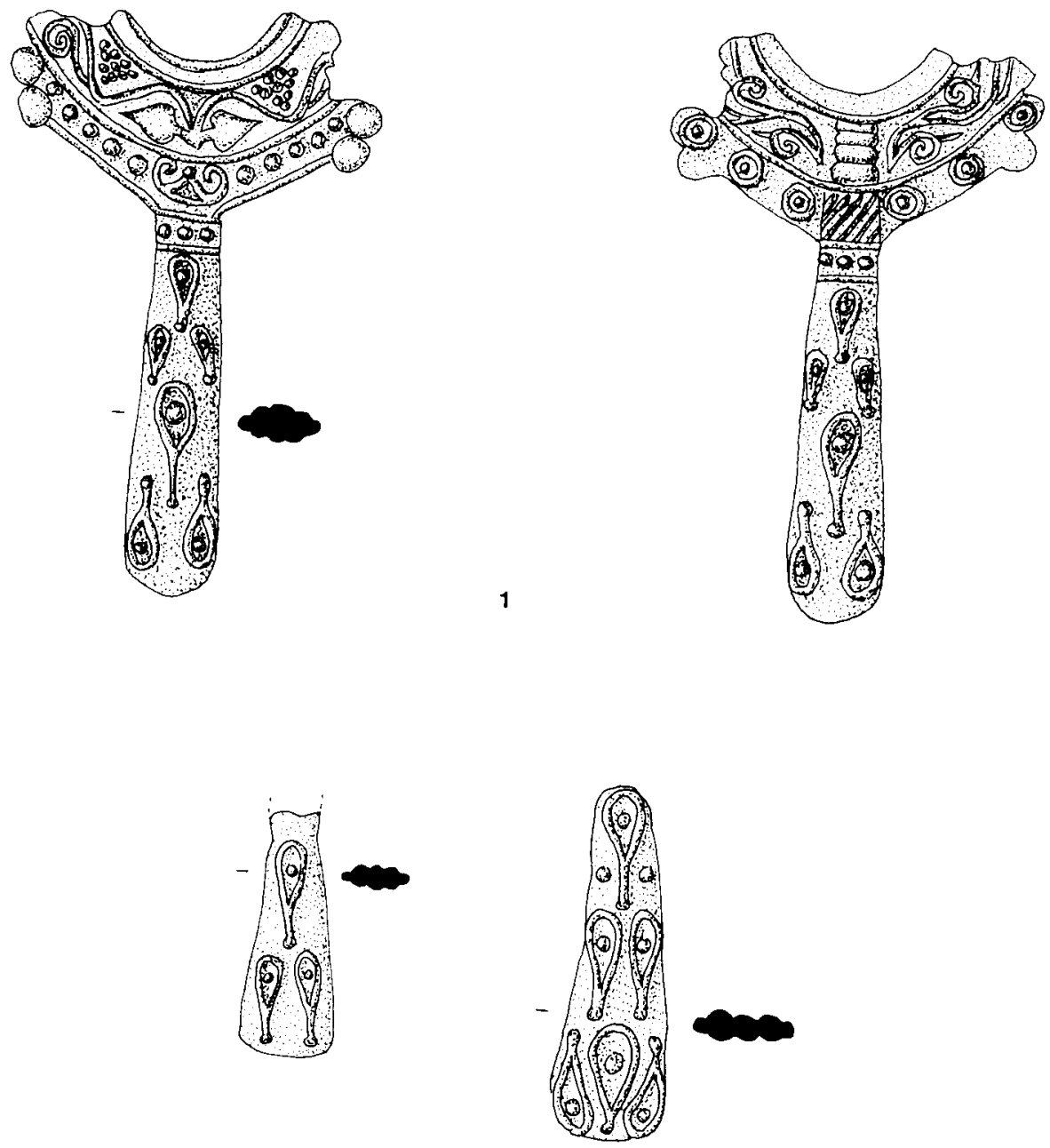

2

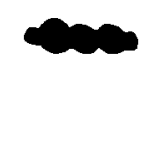

3

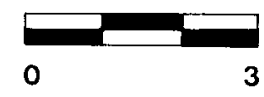

Fig. 3. Núm. 1, espejo de plomo de El Quinto (Seseña, Toledo); núm. 2 y 3 , mangos de espejos de Castillejo (Aranjuez, Madrid) y de la colección Montero, respectivamente. 
Espejos hispanorromanos de plomo. Un nuevo tipo de producción ...

los concéntricos y nuevamente roleos simples. Mango análogo a los anteriores.

Mide $8,4 \mathrm{~cm}$ de longitud máxima y $5,3 \mathrm{~cm}$ de ancho máximo.

Núm. 4 (fig. 3, núm. 2)

Mango de espejo hallado en Castillejo (Aranjuez, Madrid) y perteneciente a la Colección Cigoña. Similar al resto de las piezas catalogadas. Ostenta $3,5 \mathrm{~cm}$ de longitud conservada.

Núm. 5 (fig. 3)

Mango de espejo perteneciente a las provincias de Toledo o Cuenca, depositado en la Colección Montero. Análogo a los precedentes. Cuenta con $5,2 \mathrm{~cm}$ de longitud conservada.

\section{NOTAS INTRODUCTORIAS AL MUNDO DE LOS ESPEJOS ROMANOS}

Para las tareas inherentes al aderezo personal, el espejo se destaca como instrumento fundamental dentro de los utensilios de tocador. Puede afirmarse que no existía mujer que no poseyera al menos uno, y que incluso disponian de otros más pequeños para llevar en el bolso de mano. En el mundo antiguo se desconocía el procedimiento para lograr reflejar los objetos en el cristal, por lo que los espejos se fabricaban a partir de metales esmeradamente pulidos.

La materia prima más empleada durante el periodo romano fue el bronce. El tipo que gozó de mayor popularidad, sin contar con aquellos de disco simple, son los espejos con mango de balaustre rematado por tres hojas estilizadas, como el del Tosal de Manises (Belda, 1945, 165, lám. 74); enterramiento 282 de Valdoca (Alarcao, 1966, lám, 20, núm. 282, 2); Munigua (Vegas, 1988, 52-53) o Augst (Riha, 1986, lám. 2, núm. 13). Otras variantes conforman los vástagos cónicos, como el de Iruña (Nieto, 1958, 199, fig. 138, núm. 6); los octogonales, como el de la sepultura 1 de Monte Farrocho (Alarcao, 174, 6, lám. 1, núm. 1); o los de 
balaustre sin remate superior, así el de la tumba de la "gran estela", en Belo (París, 1926, 36, fig. 22, núm. 1).

Otro tipo de espejos, menos comunes y hasta ahora creemos que desconocidos en la arqueología hispano-romana, son los realizados en vidrio. La técnica para reflejar la materia consistía en una delgada capa de vidrio, que no suele superar los $0,03 \mathrm{~cm}$ de espesor, superpuesta a una superficie bañada en plata. Ya Plinio el Viejo menciona esta categoría de objetos (Nat. Hist., XXXVI, 193), de los que muy pocos han llegado hasta nosotros, debido a la fragilidad de tan minúscula capa de vidrio. Lo que sí se suele conservar, sin embargo, son los enmarques y las tapas que los protegian, realizados mayoritariamente, al menos en la parte occidental del Imperio, en plomo.

Por lo general suelen contar con una buena decoración, producto de la fundición en molde, adscrita a temas geométricos o sencillos. Las formas que presentan son resumibles, en líneas generales, en la morfologia del rectángulo y del círculo. Constan de dos partes bien diferenciadas: el cuerpo sustentante rematado por un mango, que cuenta con un marco abierto, donde se encaja el medallón que recibe la superficie plateada. Este medallón, que suele tener un tratamiento ornamentístico más cuidado, se adhiere al marco mediante un producto bituminoso o alguna sustancia resinosa. Aunque la mayoria de los ejemplares se caracterizan por su sencillez, existen, empero, otros especimenes conceptuales más ambiciosos desde el punto de vista estético, como algunos de los que aquí presentamos, o el encontrado en el área de la necrópolis de Ságvár (Burguer, 1966, fig. 87). Este último cuenta con un mango liso y romboidal, siendo el cuerpo de forma foliácea. El medallón posterior ostenta una decoración en relieve en la que se representan a las Tres Gracias.

Los centros de producción occidentales detectados hasta el momento se sitúan en los Balcanes (Tudor, 1959, 415-432) y en Colonia (Fremersdorf, 1939, 6-22, lám. 10). En el foco balcano se han logrado identificar algunos plumbarii, como "Lollianus" o "Brutus", gracias a las marcas dejadas en los propios objetos. Sus productos se caracterizan por ser piezas de marco circular, ornamentadas con espirales encadenadas, flanqueadas de puntos y separadas por líneas punteadas. Los espejos búlgaros presentan las mismas características tipológicas y artísticas que los hasta ahora vistos, por los que actualmente se admite la existencia de un grupo de artesanos balcano-danubianos. Otro grupo de espejos estarian vinculados con la zona panónica y occidental, donde priman los especimenes sin mango y decorados modestamente, las más de las veces con simples motivos lineales (Tudor, 1959, 421). Fitz distinguia, además, un tipo oriental ornamentado frecuentemente con pámpanos y es- 
pirales, donde suelen aparecer inscripciones en griego, y un tipo tracio cuyos motivos principales eran la guirnalda sinuosa y las hojas cordiformes (Fitz, 1957, 390). Tudor, sin embargo, al documentar en los Balcanes estos motivos decorativos definidores de los rasgos orientales, sólo nos ha dejado como parámetro válido para identificar los productos de las oficinas orientales, la aparición de leyendas en griego (Tudor, 1959, 425).

Estos grupos distribuidos en áreas geográficas concretas nos hablan de la gran difusión que lograron alcanzar este tipo de piezas que sometemos a estudio. Todos los espejos tienen un aire familiar que los homogeneiza y permiten su inmediata identificación, pero, al mismo tiempo, presentan unas peculiaridades propias que distinguen unos productos de otros. La forma del mango, o la simple aparición o no de este elemento, suele clarificar el lugar de origen del objeto. Es por ello que las clasificaciones tipológicas efectuadas hasta el momento, se basan tanto en el tipo de enmangue como en los motivos ornamentisticos que presentan. Tudor apreció 22 clases distintas de espejos plúmbeos, en las que no encajan ninguno de los espejos hispanos que conocemos, si bien es cierto que los ejemplares que tratamos responden a la misma koiné, visible en la aparición de algunas decoraciones similares a las de sus hermanos europeos, como por ejemplo: círculos con punto central, roleos, pámpanos, cráteras, hojas de hiedra, etc. Esto no lleva a realizar un estudio pormenorizado de los especimenes hispanos, debido a sus características intrinsecas, desligado del resto de sus congéneres, con los que sólo comparte la concepción primigenia del objeto. Punto que acometemos en el próximo apartado.

Respecto a la cronología de estos productos, Lloyd-Morgan, en razón a los ejemplares britanos, propone una datación que abarca desde el siglo II d.C. hasta el siglo IV, siendo para este autor el espejo plúmbeo muy común durante este período, debido a su bajo precio y a la facilidad de almacenaje, frente a los costosos y voluminosos espejos broncineos (Lloyd-Morgan, 1977, 237). Esta datación tardía podría estar avalada también por el ejemplar de Ságvár, adscrito a una necrópolis del siglo IV d.C. Tudor considera los espejos balcánicos, obras de artesanos locales, fechables entre el siglo II-III d.C., a tenor de los materiales aparecidos en el depósito de Sucidava (Tudor, 1959, 426).

\section{LOS ESPEJOS DE PLOMO HISPANOS}

Los cinco espejos hispanos presentan unas características comunes, aparte de su fabricación en plomo, que son dignas de destacar. Es por 
ello que los hemos desligado de otros grupos conocidos, presuponiéndoles una entidad definida que los separa del resto. En primer lugar sus parecidas dimensiones. La forma de los mangos son en todos ellos idénticas, así como la ornamentación de gotas que recorre el elemento, siendo esta decoración totalmente novedosa en el repertorio estético de los espejos plúmbeos. Otro nexo de unión es la repetición de motivos decorativos. La pieza del MAN y la de Seseña tienen la misma seriación de roleos con hojas de hiedra y pámpanos. Este último ejemplar de la colección privada cuenta, además, con una ornamentación peltiforme igual al espejo de La Bienvenida, con el que también comparte el tránsito entre mango y cuerpo central, mediante dos molduras que enmarcan tres esferas, para dar paso a un espacio superior con líneas transversales.

Todas estas concomitancias, unidas a la ausencia de paralelos exactos para nuestros ejemplares fuera de Hispania, nos hacen pensar, como ya hemos dicho, en un origen común.

Con esto se nos plantean nuevas incógnitas, como buscar el porqué de estas producciones en nuestro suelo y la temporalidad que las caracteriza. Al ser los ejemplares que investigamos descontextualizados, a excepción del de La Bienvenida, para el que no contamos con estatigrafía, nos obligan a rastrear su pista a través de rasgos meramente externos.

Centraremos primeramente nuestra atención en la corona radiada del espejo de Ciudad Real, para la que no contamos con ninguna aproximación formal en el resto de espejos plúmbeos conocido. Radiados ultracirculares y bicirculares aparecen frencuentemente, sin embargo, en especimenes de bronce del Alto Imperio (Riha, 1986, lám. 1, núms. 1 y 2; lám. 2, núm. 13; Deimel, 1987, 254, fig. 63, núm. 1). La sepultura 115 del "Campo de los olivos" (Carmona) proporcionó una pieza broncínea, con mango clásico abalaustrado y terminado en tres hojas, cuyo disco tiene unos arqueados radiales finalizados en molduras (Bonsor, 1931, 62 y 63). La estructura de apéndices triangulares rematados por una esfera parece ser menos común. El espejo de plata de Boscoreale, firmado por el artista M. Domitius Polygnos y con un medallón decorado con un busto de ménade, tiene trece dentados semejantes (De Ridder, 1924, 215, lám. 32, núm. 2.158). En una sepultura de Las Canteras (Sevilla) apareció un gran espejo de bronce con 15 apéndices (Fernández Chicarro, 1952, 190, fig. 73). Representaciones iconográficas de este tipo encontramos en un mosaico de El-Jem y en un altar de Roma. El mosaico de "Thysdrus" nos muestra a Venus saliendo del baño, mientras un erote sostiene un espejito frente a la diosa (Slim, 1985, 48). Este utensilio es de forma circular y de él emergen una serie de haces simples. El altar del Museo de las Termas merece unas consideraciones más extensas. 
Es un ara funeraria tradicional, cuyos lados principales están ornamentados con la representación de unas ménades en uno, y la dextrarum iunctio en el otro. Los laterales ostentan camilli portadores de objetos sagrados (García y Bellido, 1979, 284, figs. 466-469). La pieza se fecha en la primera mitad del siglo । d.C. En la cara de las ménades figura una guirnalda superior en la que, como motivo central, aparece un espejo de mango abalaustrado y cuerpo en estrella de siete puntas (Godwin, 1981, 142, núm. 109). Las puntas de la estrella están constituidas por triángulos rematados en esferas, y dejan un espacio, también triangular, entre éstas y la zona central. El motivo ornamental del espejo se encuentra sustituido en los otros tres lados por sendas cráteras. Como se puede observar, la estructura del espejo de La Bienvenida y la del que aparece en el altar son muy semejantes, a excepción del mango. Otro rasgo común a estos dos objetos es la presencia de cráteras.

Ménades y cráteras se encuentran asociadas al culto de Dionisos. Dionisos era, en un principio, simplemente el dios del vino; luego se convirtió en el dios de la vegetación y del calor húmedo; después apareció como el dios de los placeres, como la divinidad de la civilización; y por último, según la concepción órfica, como modalidad de dios supremo (Guirand, 1971, 221). Aspectos simbológicos inherentes a esta divinidad se encuentran plasmados en casi todos los espejos que tratamos.

La pieza del MAN posee erotes pisando uvas, y retorcidos sarmientos de vid, cargados de pámpanos y racimos. Esta última decoración es muy semejante a la que aparece en una de las pilastras del tetrapylon de Leptis, de época de los Severos, sólo que aquí los roleos se ven complementados por angelotes que ascienden hacia las parras (García y Bellido, 1979, 558, fig. 989). El motivo transicional entre mango y espejo puede identificarse, asimismo, como la representación del extremo de un tirso. Un elemento parecido, empuñado por el propio Dionisio, encontramos en un relieve de Herculano (Guirand, 1971, 222). A veces el tirso se rodea de elementos filiformes, como sucede en nuestro objeto y en el conocido fresco de la "Villa de los misterios", en Pompeya.

El espejo de La Bienvenida cuenta con una crátera y tiene su paralelo iconográfico más cercano en el relieve de contenido dionisiaco, que antes citamos. La crátera es un motivo decorativo común en todo el arte romano, usado en punzones de sigillata (Garabito, 1978, 581, fig. 124), ornamentación de vasos metálicos (Tassinari, 1975, 51, lám. 23, núm. 103), etc. Es la musivaria donde polifera abundantemente, no aportando datos cronológicos concretos, pues se representaron desde antiguo, aunque su época de florecimiento se inscribe en el mundo tardorromano. Cráteras de cuerpo agallonado y tránsito hacia el cuello decorado apa- 
recen, a título de ejemplo, en los siguientes pavimentos: mosaicos $B$ de la "villa" de Baños de Valdearados (Burgos), fechado en la primera mitad del siglo $v$ d.C. (Argente, 1979, 61, lám. 10, núm. 2); fragmento de Carmona, datado a fines del siglo $\|$ d.C. o comienzos de la centuria siguiente (Blázquez, 1982, 35, lám. 14), etc. Uno de los espejos de plomo del depósito de Sucidava cuenta como motivo decorativo transicional, entre mango y cuerpo, con una crátera agallonada muy parecida a la del ejemplar de Ciudad Real (Tudor, 1959, 430, fig. 4, 24).

Del ejemplar de Seseña, por estar incompleto, poco podemos decir. Sin embargo, podemos comentar la faja de espirales enlazadas que terminan en hojas de hiedra y pámpanos. Según Blázquez, este tema es frecuente en mosaicos de la segunda mitad del siglo ॥ d.C. (Blázquez, 1981, 86), aunque perdura en el sigio III y IV d.C. (Blázquez, 1981, 35). Tallos serpenteantes con hojas de hiedra acompañan a un mosaico de Dioniso hallado en la calle Hermanos González Murga (Córdoba), correspondiente a las postrimerías del siglo ॥ d.C. (Blázquez, 1981, 26, fig. 8). Otro pavimento cordobés, esta vez de Alcolea, decorado con thyasos báquico, tiene a sus personajes dispuestos radialmente y separados por espacios triangulares con hojas de hiedra. Se fecha, también, en la segunda mitad del siglo ॥ d.C. (García y Bellido, 1965, 7 y ss.). A esta misma cronología apunta una orla vegetal de Carmona (Blázquez, 1982a, 35, lám. 14, núm. 20). Decoraciones semejantes se hallan también representadas en los espejos plúmbeos de los Balcanes, con una datación coetánea a la de los pavimentos musivarios aludidos.

La nota más caracteristica del espécimen depositado en el MAN es su medallón posterior donde aparece la representación plástica del jinete y vencido. Esta iconografía resulta también novedosa respecto al resto de los espejos de plomo europeos. Las escenas bélicas, en el arte público romano, comienzan en fechas muy tempranas, y las tenemos ya presentes en el siglo $\|$ a.C. en un relieve situado cerca del templo de Apolo, en Delfos (Henig, 1985, 83), que muestra escenas de la batalla de Pydna (108 a.C.). Máximos exponentes de este arte son la columna trajana o la de Marco Aurelio. Su utilización en los monumentos públicos no nos sirve para datar, pues es una caracteristica fundamental en todo el Imperio, la plástica relacionada con hechos históricos y entre ellos las batallas.

Su empleo como decoración de sarcófagos tampoco es un elemento de cronología válido, ya que este sistema de enterramiento se generaliza a partir del siglo II d.C., faltando, por tanto, ejemplares anteriores. Se constata, sin embargo, lo popular del tema a finales del reinado de Marco Aurelio, sobre todo en los sarcófagos producidos en el taller de Roma. EI 
difunto es plasmado en un friso como general victorioso en un enfrentamiento entre romanos y bárbaros. Esta iconografía desapareció en el siglo III d.C. (Hening, 1985, 83). Buenos ejemplos de sarcófagos de este tipo son los de Villa Amendola (García y Bellido, 1979, 142, fig. 871), Pietralata (García y Bellido, 1979, 497-498, fig. 874) y Portonaccio (Henig, 1985, fig. 80). En este último, destinado a un general de Marco Aurelio, se aprecian jinetes en actitudes semejantes a las del espejo del MAN. Pese a que ya no se representa al difunto, existen sarcófagos con escenas de batallas y cautivos, incluso en el siglo iv d.C., como el llamado de Santa Helena.

En numismática, la figura del jinete se usó casi desde los comienzos de la amonetación. En la época republicana, el personaje se presenta a cabalio, como si de un monumento ecuestre se tratara. Un denario de Manio Aemilio Lepido (107 a.C.) (Cohen, 1976, 9, lám. 1, Aemilia 3), ubica al animal sobre una estructura de tres arcos; en otro denario, de Lucio Lentulo y Cayo Marcelo (49 a.C.), el motivo sustentante es una proa de nave con trofeo (Cohen 1976, 109, lám. 15, Cornelia 28). Jinete $y$ vencido aparecen con relativa frecuencia en los reversos de las monedas, como tenemos en un denario de Publio Fonteyo y Manio Fonteyo (60 a.C.) (Cohen, 1976, 141, lám. 17, Fonteia 9), con caballo que pisotea a dos enemigos, así como en denarios de la familia Licinia (48-42 a.C.) (Cohen, 1976, 183, lám. 24, Licinia 6 y 7) con jinete a la carrera arrastrando a un bárbaro por los cabellos, o en un antoniano de Probo (276282 d.C.), donde el emperador, a caballo, sostiene una lanza mientras un cautivo está sentado delante del animal (Sear, 1974, 277, lám. 9, núm. 3238 A). Será bajo Marco Aurelio y su co-regente Lucio Vero, cuando proliferen las representaciones de los emperadores en escenas militares, motivado por la constante repetición de guerras fronterizas. En una moneda de Vero, el gobernante alanzea a un enemigo caido, en posición parecida al medallón del espejo que tratamos. Durante la mayor parte del siglo III d.C. se muestra a los emperadores a caballo, vestidos a lo militar y con la mano derecha levantada. Este tipo fue lentamente abandonado a finales de dicho siglo, para sobrevivir en la centuria siguiente, mezclado con imágenes adoptadas de la Nueva Fe (Sear, 1974, 27).

\section{SIGNIFICADO Y FUNCION DE LOS ESPEJOS HISPANOS DE PLOMO}

La funcionalidad de estos objetos ha sido vinculada, en ocasiones, con las labores inherentes al aderezo personal, destinándolo preferente- 
mente al retoque del maquillaje por parte de la dama romana, quien lo portaría consigo, en el bolso, debido a su reducido tamaño. A esta teoría se opone, sin embargo, el sentido común y algunos hallazgos arqueológicos. Por una parte, si bien es cierto que sus dimensiones to hacen favorable para el transporte cotidiano, empero, su fragilidad lo convierte en inadecuado para una manipulación excesiva o poco cuidadosa. En efecto, el espesor de estos espejos suele ser bastante delgado, to que unido a la poca consistencia del plomo, facilita su rotura. La conjetura inmediata podría ser su uso como espejo de mano, depositado permanentemente en el tocador o resguardo en un estuche apropiado. Pero a esta última hipótesis se opone el minúsculo diámetro de la superficie vitrea reflectante, para la que Lloyd-Morgan ha calculado una media de 3 a $5 \mathrm{~cm}$ (Lloyd-Morgan, 1977, 237), campo visual demasiado pequeño, por tanto, como para permitir una visión general en las tareas del aderezo, función que cumplen los espejos de tocador.

Estas irregularidades han hecho discutir a los especialistas la función específica de esta clase de espejos llevándoles a otorgarles un contenido espiritual. Tanto Fitz, como Nowotny, los consideran inmersos dentro de la categoría de ex-votos u objetos relacionados con las prácticas ocultas (Fitz, 1957, 383; Nowotny, 1910, 124), lo que explicaría su aparición en ámbitos culturales y funerarios. En este sentido la aparición de depósitos votivos, donde aparecieran este tipo de espejos, podría aclarar definitivamente el problema. Efectivamente, en el santuario dedicado a las Ninfas en Orochak, en el de Zeus y Hera en Copilovtsi, o el santuario tracio de Dulévo, han ofrecido especímenes de esta clase en sus depósitos de ofrendas. El mismo hallazgo de 68 espejos plúmbeos en una zanja de Sucidava hace pensar a su excavador en la posibilidad de que procedan de un santuario en ruinas durante el siglo III d.C., debido a los acontecimientos tumultuosos de la zona (Tudor, 1959, 425-426). Entre los espejos de Sucidava encontramos uno con una invocación al dios Dionisos, que reza: DAVINUM (ida vinum!) (Tudor, 1959, 431, fig. 5, núm. 31). Asimismo, entre la tierra que envolvía los espejos se encontró un molde de cerámica que representaba la escena clásica de Dionisos dando de beber a una pantera en una crátera. Quizá este santuario balcánico estaba dedicado al propio Dionisos, como propone Tudor.

En los espejos de plomo hispanos parece manifestarse un gusto por los motivos iconográficos de corte dionisíaco. Hay que tener en cuenta que la simbología característica de Dionisos, es un tema propicio para su plasmación en la clase de objetos que estudiamos, ya que este utensilio también se encuentra asociado al mito de este dios. En una pyxis de marfil del Museo de Bologna, fechada en el siglo v d.C. (Godwin, 1981, 
135, núm. 98), aparece la escena que pasamos a describir. El joven Dionisos está sentado sobre un trono mirándose apaciblemente en un espejo que sostiene un servidor, mientras que dos corybantes armados, los cuales deberian defender al dios infante, se preparan para asesinarle y desmembrarle. La imagen de Dionisos fascinado por el espejo, seguida de su muerte provisional, representa el destino del alma humana, la cual, de acuerdo con la doctrina platónica, mira desde su morada en los cielos y ve su engañoso reflejo en la superficie del mundo material. Atraído, como Narciso, por la belleza de su propia imagen, el dios intentará aferrarse a ella, pero en su esfuerzo cae vencido. Se trata de un transunto de la mortalidad del alma. En esta caja ebúrnea, la concepción de Dionisos está ya muy alejada del rústico dios del vino y la alegría. Por reflejo del misticismo órfico se habia introducido un nuevo elemento en su culto, la "pasión", que nace de la asimilación de la divinidad con Zagreo. Dioniso-Zagreo, como dios que es destruido, que desaparece, que abandona la vida y renace después, simboliza la vida universal y la inmortalidad (Guirand, 1971, 226). Una espléndida versión de la pasión de DionisoZagreo se encuentra representada en la "villa de los misterios".

La vinculación clara de los espejos hispanos con un ambiente cultural es una incognita sin resolver. Sólo el espejo de La Bienvenida procede de una excavación científica, aunque su adscripción a una zona en proceso de investigación nos resta cualquier conclusión válida. Respecto a los otros ejemplares conocidos, nada sabemos de su contexto arqueológico, aunque el excelente estado de conservación de la pieza del MAN hace sospechar su aparición dentro de un ajuar funerario. Por tanto, sólo la plasmación de motivos iconográficos alusivos a Dionisos vendría a apoyar esta hipóstesis de trabajo, cuyo peso especifico tendrá que ser comprobado en un futuro.

\section{CONCLUSIONES Y CRONOLOGIA}

Tras el proceso de catalogación y estudio de esta serie de espejos romanos hemos logrado identificar un nuevo tipo de producción metalistera inédito en la bibliografía española. Las diferencias que presentan las piezas hispanas creemos que son 10 suficientemente definitorias como para plantear la creación de un nuevo grupo de espejos plúmbeos a los que otorgar el titulo eventual de hispano-romanos. El lugar de producción de los mismos debe ubicarse en el extremo occidental del Europa, y con casi toda seguridad en Hispania, ya que no conocemos ejemplares simi- 
lares en la Gallia o Italia, siendo los especimenes britanos diferentes a los nuestros. Incluso podriamos eventuar que el foco de irradiación debe buscarse en la Meseta, pues alli se han encontrado la totalidad de los mismos.

La idea embrionaria de esta producción plúmbea de raíz hispana parece derivarse de los espejos realizados en bronce, al menos para el caso del espécimen de La Bienvenida, cuyos paralelos conceptuales más próximos se hallan en las piezas broncíneas. El espejo del altar del Museo de las Termas, su paralelo más exacto, cuenta con un mango abalaustrado característico de los ejemplares de bronce. Asimismo, el espíritu ornamentístico que inspira al espejo del MAN se basa en las concepciones de obras broncineas.

Cronológicamente, la fabricación de estos productos no debe ser anterior a la segunda midad del siglo II d.C., como parece desprenderse de las manifestaciones artísticas con las que guardan relación. La fecha final, sin embargo, no es desconocida, aunque el hecho de que estén inmersos en la misma dinámica cronológica del resto de sus congéneres europeos podría hacer pensar que prolongaron su vida hasta el siglo IV d.C. Aunque para el caso hispano nos inclinamos a pensar en una temporalidad algo menos dilatada, basándonos en su no aparición entre los ajuares de las necrópolis correspondientes a la cuarta centuria. El grueso de la producción se encontraría, por tanto, entre la segunda mitad del siglo II d.C. y el siglo III de nuestra era.

Por último, queremos resaltar que sólo la aparición de nuevos hallazgos inmersos en secuencias estratigráficas nacionales podrán arrojar más luz sobre este grupo de objetos individualizados del resto de su especie. 
Espejos hispanorromanos de plomo. Un nuevo tipo de producción ...

\section{BIBLIOGRAFIA}

Alarcao, J., y Alarcao A., (1966): “O espólio da necropole de ValdoCa», Conímbriga, 5.

ARgente Oliver J. L. (1979): «La villa tardorromana de Baños de Valdearados (Burgos)", Excavaciones Arqueológicas en España, 100.

BeLdA, A. (1945): "El Museo Arqueológico Provincial de Alicante", Memorias de los Museos Arqueológicos Provinciales, 6.

BLÁzoUEZ, J. M. (1981): «Mosaicos romanos de Córdoba, Jaén y Máladaga", Corpus de mosaicos de España, 3. Madrid.

- (1982 a): "Mosaicos romanos de Sevilla, Granada, Cádiz y Murcia", Corpus de mosaicos de España, 4. Madrid.

- (1982 b): «Mosaicos romanos de la Real Academia de la Historia, Ciudad Real, Toledo, Madrid y Cuenca", Corpus de mosaicos de España, 5. Madrid.

Bonsor, G. (1931): An archaeological sketch-book of the necropolis at Carmona. Nueva York.

Burger, A. S. (1966): "The late roman cementery at Ságvár», Acta Archaeologica Hungárica, 18.

COHEN, H. (1976): Descripción general de las monedas de la república romana. Madrid.

DeIMEL, M. (1987): Die Bronzekleinfunde vom Magdalensberg. Klagenfurt. DE RIDDER, A. (1924): Catalogue sommaire des bijoux antiques. París.

Fernández ChICARRO, C. (1952): “Actividades arqueológicas en Andalucia», Archivo Español de Arqueologia, 25.

FITZ, J. (1957): “Intercisa II (Dunapentele)", Arch-Hung, 36.

Fremersdorf, F. (1939): “Erzeugnisse Kölner Manufakturen in den Funden von Kastell Saalburg und Zugmantel», Saalburg Jahrbuch, 9. 
Garabito, T. (1978): “Los alfares romanos riojanos. Producción y comercialización", Biblioteca Praehistorica Hispánica, 16.

Garcia y Bellido, A. (1965): "Los mosaicos de Alcolea (Córdoba), Boletín de la Real Academia de la Historia, 156.

- (1979): Arte Romano. Madrid.

GodWIN, J. (1981): Mystery religions in the ancient world. Londres.

GUIRAND, F. (1971): Mitología general. Barcelona.

HENIG, M. (1985): El arte romano. Barcelona.

LLOYD-Morgan, G. (1977): "Mirrors in Roman Britain", BAR British Series, 41.

- (1981): The mirrors. The collections in the Rijksmuseum GM Kam at Nijmegen, 9.

Nieto Gallo, G. (1985): El oppidum de Iruña.

Paris, P. (1926): Fouilles de Belo (Bolonia, Province de Cadix) (19171921). París.

RIHA, E. (1986): "Römisches Toilettgerät und medizinische Instrumente aus Augst und Kaiseraugst", Forschungen in Augst, 6.

SEAR, A. (1974): Roman coins. Londres.

SLIM, H. (1985): “Thysdrus (El-Jem), una gran ciudad romana de África: La ciudad y su anfiteatro", Revista de Arqueologia, 50.

TASSINARI, S. (1975): "La vaiselle de bronze romaine et provinciale au Mussee des Antiquites Nationales", Suplemento a Gallia, 29.

TUDOR, D. (1959): “Le Depot de mirois de verre double de plomb trouvé à Sucidava", Dacia, 3.

VAN BuCHEM, H. J. H. (1976): “Convexe Spiegeltjes", Numaga, 23.

VEGAS, M. (1988): “Mulva II. Die Südnekropole von Munigua Grabungskampagnen 1977 bis 1983", Madrider Beiträge, 15. Mainz am Rheim.

VV.AA. (1990): Catálogo de la exposición "Los bronces romanos en España". Madrid. 